\title{
AURC Dosing to Last Concentration Normalized by Surface Area
}

National Cancer Institute

\section{Source}

National Cancer Institute. AURC Dosing to Last Concentration Normalized by Surface

Area. NCI Thesaurus. Code C92348.

The area under the urinary excretion rate curve (AURC) from time zero to the last measurable rate, divided by the surface area. 